\title{
The inheritance of chemical phenotype in Cannabis sativa $\mathrm{L}$. (IV): cannabinoid-free plants
}

\author{
E. P. M. de Meijer · K. M. Hammond • \\ A. Sutton
}

Received: 28 September 2008/Accepted: 15 January 2009/Published online: 31 January 2009

(C) Springer Science+Business Media B.V. 2009

\begin{abstract}
A genetic factor that blocks the cannabinoid biosynthesis in Cannabis sativa has been investigated. Crosses between cannabinoid-free material and high content, pharmaceutical clones were performed. $F_{1} s$ were uniform and had cannabinoid contents much lower than the mean parental value. Inbred $\mathrm{F}_{2}$ progenies segregated into discrete groups: a cannabinoid-free chemotype, a chemotype with relatively low cannabinoid content and one with relatively high content, in a monogenic 1:2:1 ratio. In our model the cannabinoid knockout factor is indicated as a recessive allele $o$, situated at locus $O$, which segregates independently from previously presented chemotype loci. The genotype o/o underlies the cannabinoid-free chemotype, $O / O$ is expressed as an intermediate, low content chemotype, and $O / O$ is the genotype of the high content chemotype. The data suggests that locus $O$ governs a reaction in the pathway towards the phenolic cannabinoid precursors. The composition of terpenoids and various other compound classes of cannabinoid-free segregants remains unaffected. Backcrossing produced cannabinoid-free homologues of pharmaceutical production clones with potential applications in pharmacological research. A new variant of the previously presented allele ' $B_{0}$ ', that almost completely obstructs the conversion of $\mathrm{CBG}$
\end{abstract}

E. P. M. de Meijer $(\varangle)$ - K. M. Hammond · A. Sutton GW Pharmaceuticals Plc., Porton Down Science Park, Salisbury, Wiltshire SP4 0JQ, UK

e-mail: edm@g-pharm.com into CBD, was also selected from the source population of the cannabinoid knockout factor.

Keywords Cannabinoids - Cannabis . Chemotype $\cdot$ Genotype $\cdot$ Knockouts

\section{Introduction}

Cannabinoid biogenesis

Cannabis plants accumulate cannabinoids as carboxylic acids in the secretory cavity of glandular trichomes. Here, these compounds will be indicated by the abbreviations for their neutral forms. The most common cannabinoids, those with pentyl side chains, are cannabidiol (CBD), delta 9-tetrahydrocannabinol (THC), cannabichromene (CBC) and cannabigerol (CBG). The first specific step in the pentyl cannabinoid biosynthesis is the condensation of the terpenoid moiety geranylpyrophosphate (GPP) with the phenolic moiety olivetolic acid (OA; 5-pentyl resorcinolic acid) into CBG. This reaction is catalysed by the enzyme geranylpyrophosphate:olivetolate geranyltransferase (GOT; Fellermeier and Zenk 1998). Precursors for GPP are isopentenyl pyrophosphate (IPP) and dimethylallyl pyrophosphate (DMAPP). These can originate from the mevalonate pathway (MVA) that is located in the cytoplasm and the deoxyxylulose pathway (DOX) that operates in the plastid compartments. According 
to Fellermeier et al. (2001), the GPP incorporated into cannabinoids is derived via the DOX pathway of the glandular trichome plastids. The phenolic moiety OA is generated by a polyketide-type mechanism. Raharjo et al. (2004a) suggest that n-hexanoyl-CoA and three molecules of malonyl-CoA condense to a $\mathrm{C}_{12}$ polyketide, which is subsequently converted into $\mathrm{OA}$ by a polyketide synthase. The condensation of n-hexanoylCoA and two, instead of three, molecules of malonylCoA, results in a $\mathrm{C}_{10}$ polyketide. This is subsequently cyclisised into divarinic acid (DA; 5-propyl resorcinolic acid) by a polyketide synthase (Raharjo et al. 2004b). Cannabinoids with propyl side chains result if GPP condenses with DA, into cannabigerovarin (CBGV).

CBG is the precursor for THC, CBD and CBC. For each CBG conversion an enzyme has been identified: THC acid synthase (Taura et al. 1995), CBD acid synthase (Taura et al. 1996) and CBC acid synthase (Morimoto et al. 1997, 1998). These enzymes are not selective for the length of the alkyl side chain and convert $\mathrm{CBGV}$ into the propyl homologues of CBD, THC and $\mathrm{CBC}$, which are indicated as cannabidivarin (CBDV), delta 9-tetrahydrocannabivarin (THCV) and cannabichromevarin (CBCV), respectively (Shoyama et al. 1984).

de Meijer et al. (2003) considered the total cannabinoid content as a polygenic character, that is heavily affected by the environment and shows a Gaussian distribution within the progenies described so far. The cannabinoid composition shows discrete distributions in segregating progenies and is under mono or oligogenic control. de Meijer et al. (2003), de Meijer and Hammond (2005) and de Meijer et al. (2009) constructed a genetic model for the regulation of the conversion and accumulation of $\mathrm{CBG}(\mathrm{V})$.

\section{Cannabinoid-free Cannabis}

In the context of a Ukrainian fibre hemp breeding program, Gorshkova et al. (1988) examined the relationship between the morphology of glandular trichomes on the Cannabis bracteoles and the cannabinoid content. According to this report, plants lacking glandular trichomes and plants carrying trichomes with white heads contain no cannabinoids. Plants with transparent trichomes with heads in the yellow-orange to brown colour range were found to be rich in cannabinoids. Since then, Ukrainian plant breeders have reported several times on the existence of cannabinoid-free materials (Virovets et al. 1991, 1997; Virovets 1998). Pacifico et al. (2006) analysed individual plants from the cultivar USO-31 (Virovets 1996) and found that cannabinoids were undetectable in one-third of the individuals. The French fibre cultivar 'Santhica 23' was claimed to be devoid of cannabinoids, incorrectly indicated as alkaloids (Anonymous 1996) and in another French cultivar, Epsilon 68, Pacifico et al. (2006) could not detect cannabinoids in a minority of the plants $(<10 \%)$.

A confusing paper by Sytnik and Stelmah (1999) may address the genetic mechanism underlying the cannabinoid-free chemotype. As outlined by Hillig (2002), these authors do not consider cannabinoid composition independently and genetically distinct from the total cannabinoid content. Hillig interpreted their experiment as concerning a dihybrid cross between parents with contrasting total cannabinoid contents (low and high) and with contrasting cannabinoid compositions (low and high $\mathrm{CBD} / \mathrm{THC}$ ratios). In an alternative understanding presented by Mandolino (2004) the paper's focus is on the segregation patterns of the discrete chemotypes 'with cannabinoids present' and 'without cannabinoids'. Following the latter interpretation, Sytnik and Stelmah found that a monogenic mechanism determines if the chemotype is with or without cannabinoids, and that the allele encoding cannabinoid presence dominates that encoding absence. While there are similar problems of interpretation with the paper by Virovets et al. (1997), the same conclusion can be drawn from it. de Meijer et al. (2003) hypothesised an allelic locus $A$ that governs the pathways to either $\operatorname{CBG}\left(A_{\mathrm{pe}}\right)$ or $\operatorname{CBGV}\left(A_{\mathrm{pr}}\right)$ and speculated that this same locus could also carry a 'null' allele preventing the cannabinoid synthesis.

Two physiological conditions could make a plant cannabinoid-free: (1) a disrupted morphogenesis of glandular trichomes that, according to Sirikantaramas et al. (2005), are essential structures for cannabinoid synthesis, and (2) a blockage of one or more biochemical pathways that are crucial for the formation of precursors upstream of CBG. The first condition would seriously affect the synthesis of all other secondary metabolites that are produced largely or uniquely in the glandular trichomes. The second condition could also affect metabolites other than cannabinoids, as in the case of an obstruction of the basic pathways of common precursors for different 
classes of end products. Secondary metabolites other than cannabinoids will be referred to by the term 'entourage compounds'. In relation to Cannabis this term is used to indicate compounds that accompany the active constituents (i.e. cannabinoids) and may modulate their effects, yet without themselves having affinity for cannabinoid receptors.

Aim of this work

We aim to extend the genetic model for chemotype inheritance in Cannabis (de Meijer et al. 2003, 2009; de Meijer and Hammond 2005). The previous papers focussed on the cannabinoid composition. Current emphasis is on the control of the discrete conditions of cannabinoid presence and absence. The wider biochemical implications related to cannabinoid absence are also considered.

\section{Materials and methods}

Plant materials and breeding experiments

Table 1 lists the high content parental clones used in the experiments, which are all true breeding for their chemotype and Fig. 1 summarises the experiments. A seed sample of the Ukrainian fibre hemp cultivar USO-31 was obtained via Dr. G. Mandolino (Istituto Sperimentale per le Colture Industriali, Bologna, Italy). Of 23 plants grown from this sample, five appeared devoid of cannabinoids whereas the remaining ones contained variable contents ranging from traces $(<0.01 \% \mathrm{w} / \mathrm{w})$ up to $1.3 \%$ of the dry floral tissue. The cannabinoid fraction of the latter plants consisted of CBD, CBC and CBG. In one individual, $\mathrm{CBG}$ was the predominant cannabinoid and in all others it was CBD. From the point of view of cannabinoid production, all USO-31 plants had a very poor morphological appearance and it was not evident that plants in which cannabinoids were not detectable and those in which they were just so, belonged to different genotypes. Inbred seeds from the two relative best individuals, both with only a cannabinoid trace $(0.01-0.02 \%)$ were pooled. This pool of inbred material was used to pollinate the high content clones M35 and M84. Apart from the inheritance of cannabinoid content, the cross with the THCV predominant M35 also investigated the

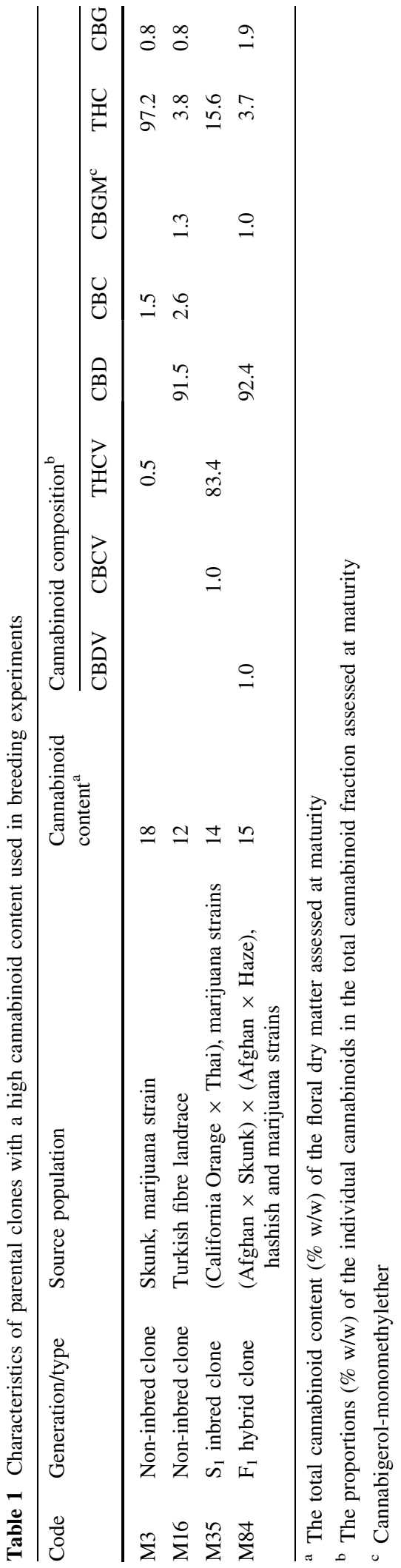


Fig. 1 Scheme of breeding process and experiments

Self-fertilisation of 23 USO-31 seedlings

Pooled inbred progenies of two individuals with very low cannabinoid content were used to pollinate the high content clones M35 and M84

M84 x USO-31 offspring $=2003.8 \mathrm{~F}_{1}$

M35 x USO-31 offspring $=2003.17 \mathrm{~F}_{1}$

Both progenies were subjected to line selection

$\mathrm{F}_{2} \mathrm{~s} 2003.8 .21$ and 2003.17.19 were used for mono- and dihybrid segregation studies and chemical comparison of segregant bulks (various compound classes)

Fixed cannabinoid-free $\mathrm{F}_{3}$ lines, 2003.8.21.76 and 2003.17.19.67, were selected and used to pollinate the high content pharmaceutical production clones M3 and M16 M3 x 2003.8.21.76 = 2005.45 $\mathrm{F}_{1}$ M16 x 2003.8.21.76 $=2005.46 \mathrm{~F}_{1}$ M3 x 2003.17.19.67 $=2005.47 \mathrm{~F}_{1}$ M16 x 2003.17.19.67 $=2005.48 \mathrm{~F}_{1}$

A single plant with good agronomic properties and resemblance to the appropriate production clone was selected from each of the four $F_{1} s$. The selected plants were maintained clonally and:

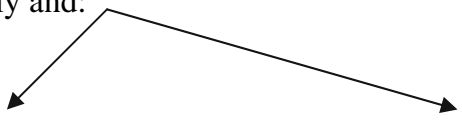

Self-fertilised to produce a large $\mathrm{F}_{2}$ for segregation study and a chemical comparison of segregant bulks (steam distilled terpenes)

2005.45.13 $\mathrm{F}_{2}$ $2005.46 .27 \mathrm{~F}_{2}$ 2005.47.9 $\mathrm{F}_{2}$ 2005.48.7 $\mathrm{F}_{2}$
Further backcrossed to the relevant production clone to produce cannabinoid-free $\mathrm{BC}_{2} \mathrm{~S}$ from which 'placebo clones' were selected (M3x(M3x(M3x(M84xUSO-31)))) (M16x(M16x(M16x(M84xUSO-31)))) (M3x(M3x(M3x(M35xUSO-31)))) (M16x(M16x(M16x(M35xUSO-31)))) possibility that a cannabinoid knockout factor may be an allele of a hypothesised locus that controls the cannabinoid alkyl chain length.

A cannabinoid-free inbred $\mathrm{F}_{3}$ line was selected from both of the resulting cross progenies and used in a backcrossing experiment with the pharmaceutical production clones M3 and M16. Large $F_{1}$ and inbred $\mathrm{F}_{2}$ progenies were produced to allow a profound study of chemotype segregation. The practical objective of this backcrossing was to obtain cannabinoidfree homologues of the production clones.

Besides the monoecious USO-31, only female parents were used. In order to mutually cross and self-fertilise female plants, a partial masculinisation was chemically induced. Isolating plants in paper bags throughout the generative stage ensured selffertilisation. Distributions of chemotypes in segregating progenies were determined and $\chi^{2}$ values were calculated to test the conformity of observed segregation ratios to those expected on the basis of hypothesised models.

\section{Cannabinoid analysis}

Mature floral clusters from every individual plant considered in the breeding experiments were 
sampled. Sample extraction, GC analysis, peak identification and quantification took place as described by de Meijer et al. (2003). When it was opportune to confirm the true absence of cannabinoids, the standard analytical procedure was modified by increasing the sample weight, reducing the volume of the extraction solvent and reducing the split-ratio of the GC injector.

Chemical comparison of segregant bulks

The broader potential of the cannabinoid knockout factor to affect other compound classes was studied. For this purpose, per segregating $F_{2}$, the floral leaves, bracts and bracteoles of all the cannabinoidfree plants were pooled and homogenised, as was the floral fraction of all the plants belonging to the group with high cannabinoid contents. The separate bulks from the 2005.45.13, 2005.46.27, 2005.47.9 and 2005.48.7 $\mathrm{F}_{2} \mathrm{~s}$ were steam-distilled and the essential oil yields assessed. The mono- and sesquiterpene composition of these essential oils was analysed by Gas Chromatography with Flame Ionisation Detection (GC-FID). The relative amounts of a wide range of entourage compounds in the bulk homogenates of the 2003.8.21 and 2003.17.19 $\mathrm{F}_{2} \mathrm{~S}$ were compared by using the techniques specified below. Of these, the cannabinoid and carotenoids assay methods are validated, the rest are $\mathrm{R} \& \mathrm{D}$ methods.

\section{Gas Chromatography-Mass Spectrometry}

To obtain comparative fingerprints, GC-MS analyses were performed on a HP5890 gas chromatograph, coupled to a VG Trio mass spectrometer. The GC was fitted with a Zebron fused silica capillary column (30 $\mathrm{m} \times 0.32 \mathrm{~mm}$ inner diameter) coated with ZB-5 at a film thickness of $0.25 \mu \mathrm{m}$ (Phenomenex). The oven temperature was programmed from 70 to $305^{\circ} \mathrm{C}$ at a rate of $5^{\circ} \mathrm{C} / \mathrm{min}$. Helium was used as the carrier gas at a pressure of $55 \mathrm{kPa}$. The injection split ratio was 5:1.

\section{Gas Chromatography with flame ionisation detection}

GC profiles of terpenoids were generated in the splitless mode with a HP5890 gas chromatograph.
The GC was fitted with a Zebron fused silica capillary column $(30 \mathrm{~m} \times 0.32 \mathrm{~mm}$ inner diameter $)$ coated with ZB-624 at a film thickness of $0.25 \mu \mathrm{m}$ (Phenomenex). The oven temperature was held at $40^{\circ} \mathrm{C}$ for $5 \mathrm{~min}$, programmed to $250^{\circ} \mathrm{C}$ at a rate of $10^{\circ} \mathrm{C} / \mathrm{min}$ then held at $250^{\circ} \mathrm{C}$ for $40 \mathrm{~min}$. Helium was used as the carrier gas at a pressure of $9.2 \mathrm{psi}$. The injection split ratio was 10:1.

\section{High-performance liquid chromatography with Ultra-Violet detection}

HPLC profiles were obtained using methods specific to a variety of compound classes. All samples were analysed using Agilent 1,100 series HPLC systems Cannabinoid profiles were generated using a $\mathrm{C}_{18}$ $(150 \times 4.6 \mathrm{~mm}, 5 \mu \mathrm{m})$ analytical column. The mobile phase consisted of acetonitrile, $0.25 \% \mathrm{w} / \mathrm{v}$ acetic acid and methanol $(75: 20: 5)$ at a flow rate of $1.0 \mathrm{ml} / \mathrm{min}$ and UV profiles were recorded at $220 \mathrm{~nm}$. Carotenoid profiles were generated using a Varian Polaris $\mathrm{C}_{18}(250 \times 4.6 \mathrm{~mm}, 5 \mu \mathrm{m})$ analytical column. The mobile phase consisted of acetonitrile: methanol: dichloromethane: water at a flow rate of $1.2 \mathrm{ml} / \mathrm{min}$ and $\mathrm{UV}$ profiles were recorded at $453 \mathrm{~nm}$. Chlorophyll profiles were generated using the same column, mobile phase and flow rate described for carotenoids. UV profiles were recorded at $660 \mathrm{~nm}$. Non-polar compound profiles (triglycerides, sterols etc.) were generated by a gradient LC method using a Phenomenex Luna $\mathrm{C}_{18}$ (2) $(150 \times 2.0 \mathrm{~mm}, 5 \mu \mathrm{m})$ analytical column. The mobile phase consisted of solvent A [acetonitrile: methyl-tert-butyl-ether (9:1)] and solvent B (water) with the proportion of B decreased linearly from 13 to $0 \%$ over $30 \mathrm{~min}$ then held constant for $20 \mathrm{~min}$ at a flow rate of $1.0 \mathrm{ml} / \mathrm{min}$. The flow rate was then increased linearly to $1.5 \mathrm{ml} / \mathrm{min}$ over $40 \mathrm{~min}$ and UV profiles were recorded at $215 \mathrm{~nm}$. Polar compound profiles (phenolics) were generated by a gradient LC method using an Ace $\mathrm{C}_{18}$ $(150 \times 4.6 \mathrm{~mm}, 5 \mu \mathrm{m})$ analytical column. The mobile phase consisted of solvent A (acetonitrile: methanol, 95:5) and solvent B $(0.25 \% \mathrm{w} / \mathrm{v}$ acetic acid: methanol, 95:5). The proportion of $\mathrm{B}$ was decreased linearly from 75 to $15 \%$ over $30 \mathrm{~min}$ then held constant for $10 \mathrm{~min}$ at a flow rate of $1.0 \mathrm{ml} / \mathrm{min}$ and $\mathrm{UV}$ profiles were recorded at $285 \mathrm{~nm}$. 


\section{Results}

Breeding experiments

\section{Crosses between clones with high cannabinoid content and USO-31 offspring}

Twenty-four plants of the $2003.8 \mathrm{~F}_{1}$ were evaluated. Twenty-one had cannabinoid contents, falling within a Gaussian distribution range from 1.13 to $4.56 \%$. Three were distinct and had only trace amounts of cannabinoids, ranging from 0.02 to $0.15 \%$. Similarly, the 19 plants of the $2003.17 \mathrm{~F}_{1}$ comprised a majority of 17 individuals with a content range from 1.69 to $13.76 \%$, and two plants with traces of only $0.02 \%$. From both $\mathrm{F}_{1} \mathrm{~s}$, an individual with only a trace content was self-fertilised to produce an inbred $\mathrm{F}_{2}(2003.8 .21$ and 2003.17.19). The chemotype distributions of these $\mathrm{F}_{2} \mathrm{~s}$ are presented in Table 2. Both $\mathrm{F}_{2} \mathrm{~s}$ comprised plants that were confirmed to be devoid of cannabinoids. The remaining plants, those with cannabinoids present, were assigned to two categories on the basis of what was thought to be a discontinuity in the cannabinoid content range: a group with low contents ranging from trace amounts up to roughly $0.6 \%$ and a group with higher contents. For the 2003.8.21 $\mathrm{F}_{2}$ and over all, $\chi^{2}$ tests accepted a 1:2:1 segregation ratio. In the 2003.17.19 $\mathrm{F}_{2}$ the low content group was overrepresented and a 1:2:1 segregation ratio was rejected.

Data on the dihybrid segregation of cannabinoid presence and composition (in terms of principal cannabinoid structures, irrespective of alkyl homologues) is summarised in Table 3. Cannabinoid-free plants are omitted. For both $\mathrm{F}_{2} \mathrm{~S}$ and over all, $\chi^{2}$ tests accepted a 6:2:3:1 segregation ratio for the variants (low cannabinoid content/CBD- or THC predominant): (low cannabinoid content/CBG predominant): (high cannabinoid content/CBD- or THC predominant): (high cannabinoid content/CBG predominant).

The 17 plants of the $2003.17 \mathrm{~F}_{1}$ with the higher cannabinoid contents all contained a propyl cannabinoid proportion in the total cannabinoid fraction $\left(\mathrm{P}_{\mathrm{C} 3} ; 8.6 \leq \mathrm{P}_{\mathrm{C} 3} \leq 35.6 \%\right)$. For the two $2003.17 \mathrm{~F}_{1}$ plants with only cannabinoid traces, $\mathrm{P}_{\mathrm{C} 3}$ could not be quantified accurately, but propyl cannabinoids were visible in their chromatograms. For the 2003.17.19 $\mathrm{F}_{2}$, based on one of the latter plants, $\mathrm{P}_{\mathrm{C} 3}$ could again only be accurately assessed for the group of 16 plants with high cannabinoid content. Five $F_{2}$ plants had pure pentyl cannabinoid chemotypes $\left(\mathrm{P}_{\mathrm{C}_{3}}=0\right)$ and in the other $11, \mathrm{P}_{\mathrm{C} 3}$ ranged from 5.9 to $45.0 \%$.

\section{Crosses of confirmed cannabinoid-free lines with the production clones M3 and M16}

The cannabinoid-free $F_{2}$ individuals, 2003.8.21.76 and 2003.17.19.67, were self-fertilised to produce fixed cannabinoid-free $\mathrm{F}_{3}$ lines for backcrossing to the production clones M3 and M16. Table 4 presents the total cannabinoid contents of the four resulting $\mathrm{F}_{1} \mathrm{~s}$. Within $\mathrm{F}_{1} \mathrm{~s}$, the cannabinoid contents showed a single Gaussian distribution and were much lower than the parental means. Per $F_{1}$, one individual was selected through such criteria as resemblance to M3 or M16 and minimal monoeciousness (inherited from USO-31). To allow for further study of chemotype segregation, the selected $F_{1}$ individuals were selffertilised to produce large inbred $F_{2}$ progenies. Figure 2 presents the distribution of chemotypes in

Table 2 Segregation data for inbred $\mathrm{F}_{2}$ progenies obtained from crosses of two high content clones with USO-31 offspring

\begin{tabular}{llllllllll}
\hline $\mathrm{F}_{2}$ progeny & $\begin{array}{l}\text { Cannabinoid content } \\
\text { of the self-fertilised } \\
\mathrm{F}_{1} \text { plant }(\% \mathrm{w} / \mathrm{w})\end{array}$ & $\begin{array}{l}\text { No. of } \mathrm{F}_{2} \\
\text { plants } \\
\text { evaluated }\end{array}$ & $\begin{array}{l}\text { No. of } \\
\text { cannabinoid- } \\
\text { free plants }\end{array}$ & $\begin{array}{l}\text { Low } \\
\text { cannabinoid } \\
\text { content range } \\
(\% \mathrm{w} / \mathrm{w})^{\mathrm{a}}\end{array}$ & $\begin{array}{l}\text { No. of } \\
\text { low } \\
\text { content } \\
\text { plants }\end{array}$ & $\begin{array}{l}\text { High } \\
\text { cannabinoid } \\
\text { content range } \\
(\% \text { w/w })^{\mathrm{a}}\end{array}$ & $\begin{array}{l}\text { No. of } \\
\text { high } \\
\text { content } \\
\text { plants }\end{array}$ & $\begin{array}{l}\chi^{2} \\
\text { value }\end{array}$ & $\begin{array}{l}1: 2: 1 \\
\text { accepted } \\
P=0.05\end{array}$ \\
\hline 2003.8 .21 & 0.02 & 87 & 25 & $0.02-0.66$ & 37 & $1.29-7.32$ & 25 & 1.94 & Yes \\
2003.17 .19 & 0.02 & 88 & 14 & $0.02-0.54$ & 58 & $0.74-6.00$ & 16 & 9.00 & No \\
All & 175 & 39 & & 95 & & 41 & 1.33 & Yes \\
\hline
\end{tabular}

${ }^{a}$ Per $\mathrm{F}_{2}$, the discrimination between the low and the high content range was based on a discontinuity in the ranking of the total cannabinoid content values

b $\chi^{2}$ values were calculated to test conformity to the model of a single locus with two co dominant alleles. The $\chi^{2}$ threshold for acceptance at $P=0.05$ is 5.99 
Table 3 Dihybrid segregation in the $\mathrm{F}_{2}$ progenies obtained from crosses of the high content clones M84 and M35 with USO-31 offspring. Per chemotype category, the number of individuals is given. The cannabinoid-free group is omitted

\begin{tabular}{|c|c|c|c|c|c|c|c|}
\hline \multirow[t]{2}{*}{ Progeny } & \multicolumn{2}{|c|}{ Low cannabinoid content } & \multicolumn{2}{|c|}{ High cannabinoid content } & \multirow[t]{2}{*}{ Total } & \multirow[t]{2}{*}{$\chi^{2 \mathrm{c}}$} & \multirow{2}{*}{$\begin{array}{l}6: 2: 3: 1 \text { accepted } \\
P=0.05\end{array}$} \\
\hline & $\begin{array}{l}\mathrm{CBD}^{\mathrm{a}} \text { or } \mathrm{THC}(\mathrm{V})^{\mathrm{b}} \\
\text { predominant }\end{array}$ & $\begin{array}{l}\mathrm{CBG}(\mathrm{V}) \\
\text { predominant }\end{array}$ & $\begin{array}{l}\mathrm{CBD}^{\mathrm{a}} \text { or } \mathrm{THC}(\mathrm{V})^{\mathrm{b}} \\
\text { predominant }\end{array}$ & $\begin{array}{l}\mathrm{CBG}(\mathrm{V}) \\
\text { predominant }\end{array}$ & & & \\
\hline 2003.8 .21 & 27 & 10 & 16 & 9 & 62 & 3.39 & Yes \\
\hline 2003.17 .19 & 42 & 16 & 10 & 6 & 74 & 5.68 & Yes \\
\hline All & 69 & 26 & 26 & 15 & 136 & 3.57 & Yes \\
\hline
\end{tabular}

a Only occurring in the 2003.8.21 $\mathrm{F}_{2}$

b Only occurring in the 2003.17.19 $\mathrm{F}_{2}$

c $\chi^{2}$ values were calculated to test conformity to a model of two independent loci. According to this model one locus has an allele, encoding cannabinoid presence, and one encoding cannabinoid absence, which are co dominant. The other locus carries the dominant alleles $B_{\mathrm{D}}$ (in 2003.8.21) or $B_{\mathrm{T}}$ (in 2003.17.19), and the recessive allele $B_{0}$. Alleles $B_{\mathrm{D}}, B_{\mathrm{T}}$ and $B_{0}$ encode for CBD- and THCsynthesis, and CBG accumulation, respectively. The $\chi^{2}$ threshold for acceptance at $P=0.05$ is 7.82

Table 4 Cannabinoid contents of $F_{1}$ progenies resulting from crosses between two high content clones (P1) and two cannabinoid-free inbred lines (P2)

\begin{tabular}{lllll}
\hline $\mathrm{F}_{1}$ progeny & $\begin{array}{l}\text { No. of } \mathrm{F}_{1} \\
\text { plants } \\
\text { evaluated }\end{array}$ & \multicolumn{2}{l}{ Total cannabinoid content $(\% \mathrm{w} / \mathrm{w})$} \\
\cline { 3 - 5 } & $\mathrm{P} 1$ & $\mathrm{P} 2$ & $\begin{array}{l}\mathrm{F}_{1} \text { range } \\
\text { Min-avg-max }\end{array}$ \\
\hline 2005.45 & 57 & 18 & 0 & $0.22-0.58-1.09$ \\
2005.46 & 57 & 12 & 0 & $0.16-0.46-1.00$ \\
2005.47 & 57 & 18 & 0 & $0.24-0.45-0.75$ \\
2005.48 & 57 & 12 & 0 & $0.10-0.42-1.25$ \\
\hline
\end{tabular}

the four $\mathrm{F}_{2} \mathrm{~S}$ in terms of total cannabinoid content. The histograms show a tripartite pattern. Each progeny comprises a discrete group of cannabinoidfree plants, a group with low content plants and one with high content plants. Within each of the latter two clusters the cannabinoid contents show a Gaussian distribution and the clusters are mutually separated by either a clear-cut discontinuity or a minimum in frequency. Data on chemotype segregation is summarised in Table 5. For three $\mathrm{F}_{2} \mathrm{~s}$ and over all, $\chi^{2}$ tests accept a 1:2:1 segregation ratio for the chemotypes cannabinoid-free: low content, high content.

In terms of cannabinoid type, the 2005.45.13 $\mathrm{F}_{2}$ segregated into THC- and CBG predominant plants, in a 3:1 ratio in the low cannabinoid content group (70:23) and in the high content group (33:11). A $\chi^{2}$ test accepted a 6:2:3:1 ratio for the variants (low content/THC predominant): (low content/CBG predominant): (high content/THC predominant): (high
content/CBG predominant). The $\mathrm{CBG}$ predominant segregants had a very high purity of CBG in the total cannabinoid fraction. Analysis of a resin concentrate obtained from the pooled CBG predominant, high content plants showed the composition: CBG 98.55\%, CBGV $1.20 \%$ and CBD $0.25 \%$.

The 2005.46.27 progeny showed a fixed composition; all cannabinoid containing plants were CBD predominant. The 2005.47.9 progeny was entirely $\mathrm{THC}(\mathrm{V})$ predominant but the total proportion of propyl cannabinoids $\left(\mathrm{P}_{\mathrm{C} 3}\right)$ was variable and ranged from 0 to $65.4 \%$ in the low- and from 0 to $73.9 \%$ in the high content group. The $\mathrm{P}_{\mathrm{C} 3}$ distribution within the low and high content groups was similar. The cannabinoid containing plants of the 2005.48.7 progeny segregated into $\mathrm{CBD}(\mathrm{V})$ predominant, mixed $\mathrm{CBD}(\mathrm{V}) / \mathrm{THC}(\mathrm{V})$ and $\mathrm{THC}(\mathrm{V})$ predominant plants which could be readily discriminated by discontinuities in the $\mathrm{CBD}(\mathrm{V}) / \mathrm{THC}(\mathrm{V})$ ratio range (data not shown). The numbers of individuals in the chemotype groups (low content-CBD(V) predominant): (low content-mixed $\mathrm{CBD}(\mathrm{V}) / \mathrm{THC}(\mathrm{V})$ ): (low content$\mathrm{THC}(\mathrm{V})$ predominant): (high content-CBD(V) predominant): (high content-mixed $\mathrm{CBD}(\mathrm{V}) / \mathrm{THC}(\mathrm{V}))$ : (high content-THC $(\mathrm{V})$ predominant) were 24:54:41: 11:22:14, respectively. A 2:4:2:1:2:1 ratio, as expected in the case of independent dihybrid segregation, was accepted $\left(\chi^{2}=8.687\right.$; threshold for acceptance at $\left.P=0.05 ; \chi^{2}<11.070\right)$. In this progeny $\mathrm{P}_{\mathrm{C} 3}$ also varied and ranged from 0 to $64.6 \%$ in the low content group and from 0 to $59.2 \%$ in the high content group. The $\mathrm{P}_{\mathrm{C} 3}$ distribution within the low and high content groups was similar. 
Fig. 2 Chemotype segregation in four large $\mathrm{F}_{2}$ progenies. Bars represent the numbers of individuals with total cannabinoid contents less than or equal to the $X$-axis values (\% w/w). To improve visualisation, $X$-axis intervals increase stepwise with increasing cannabinoid content
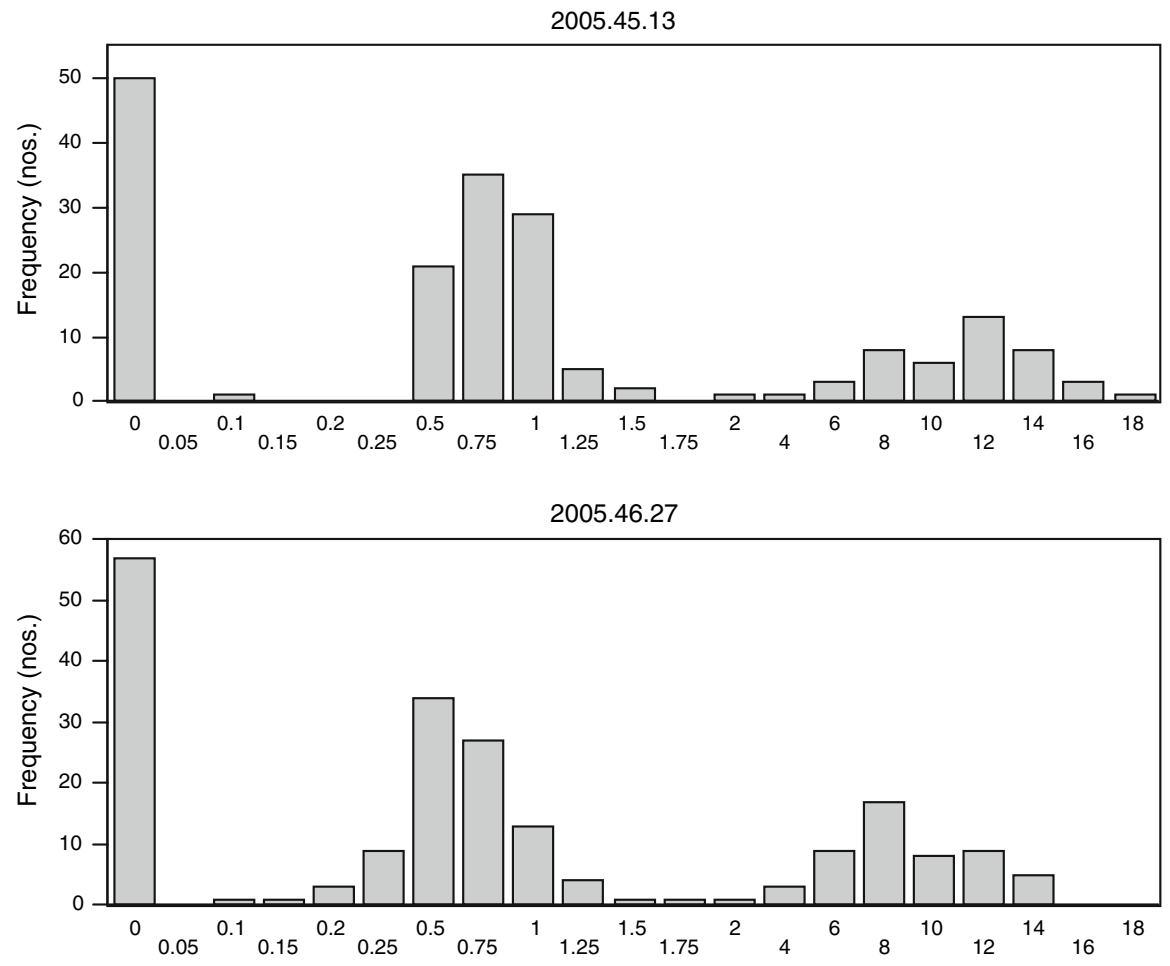

2005.47 .9
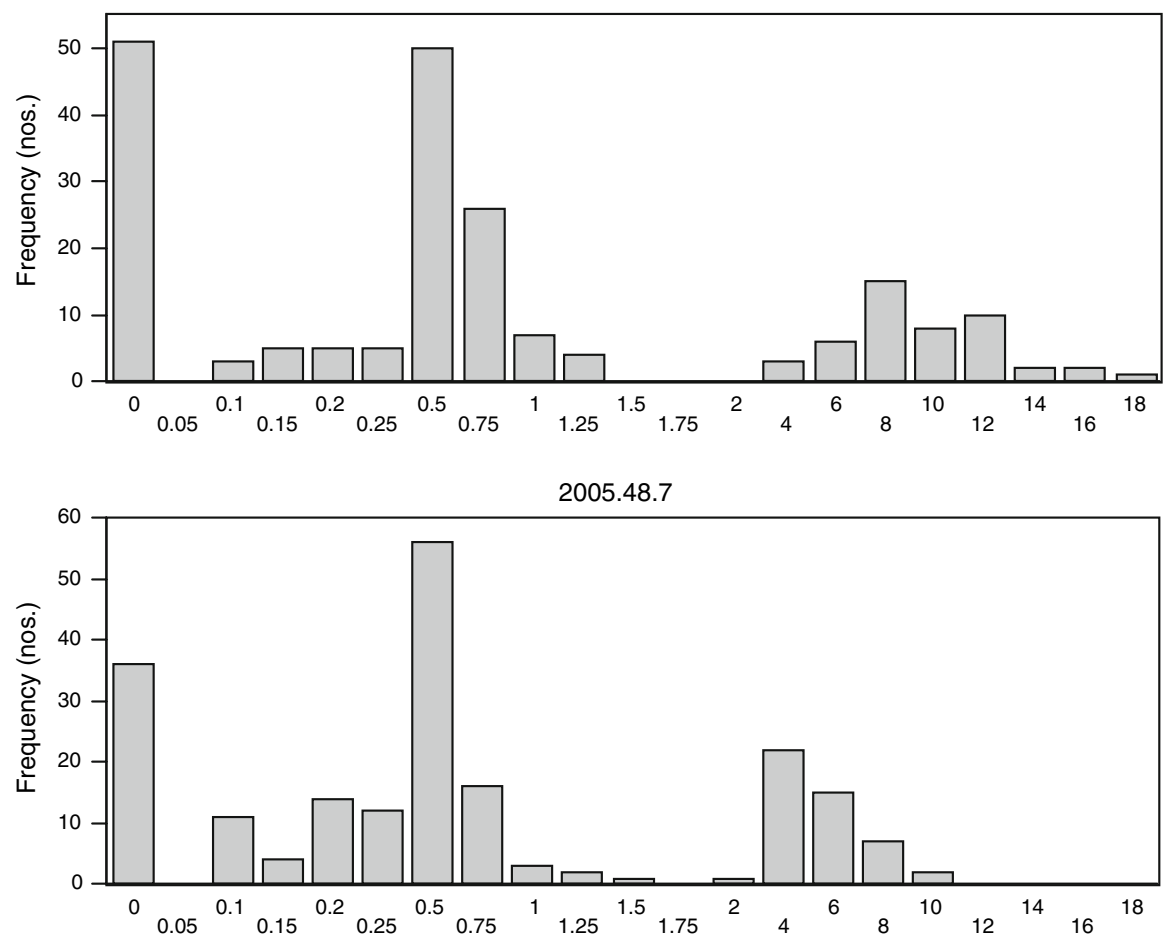
Table 5 Segregation data for $F_{2}$ progenies obtained through self-fertilisation of single $F_{1}$ individuals resultant from crosses between high content clones and cannabinoid-free inbred lines

\begin{tabular}{|c|c|c|c|c|c|c|c|c|c|}
\hline $\mathrm{F}_{2}$ progeny & $\begin{array}{l}\text { Cannabinoid content } \\
\text { of the self-fertilised } \\
\mathrm{F}_{1} \text { plant }(\% \mathrm{w} / \mathrm{w})\end{array}$ & $\begin{array}{l}\text { No. of } F_{2} \\
\text { plants } \\
\text { evaluated }\end{array}$ & $\begin{array}{l}\text { No. of } \\
\text { cannabinoid- } \\
\text { free plants }\end{array}$ & $\begin{array}{l}\text { Low } \\
\text { cannabinoid } \\
\text { content range } \\
(\% \mathrm{w} / \mathrm{w})\end{array}$ & $\begin{array}{l}\text { No. of } \\
\text { low } \\
\text { content } \\
\text { plants }\end{array}$ & $\begin{array}{l}\text { High } \\
\text { cannabinoid } \\
\text { content range } \\
(\% \mathrm{w} / \mathrm{w})\end{array}$ & $\begin{array}{l}\text { No. of } \\
\text { high } \\
\text { content } \\
\text { plants }\end{array}$ & $\begin{array}{l}\chi^{2} \\
\text { value }^{\mathrm{a}}\end{array}$ & $\begin{array}{l}1: 2: 1 \\
\text { ratio } \\
\text { accepted? }\end{array}$ \\
\hline 2005.45 .13 & 0.89 & 187 & 50 & $0.09-1.48$ & 93 & $1.76-16.96$ & 44 & 0.39 & Yes \\
\hline 2005.46 .27 & 0.47 & 203 & 57 & $0.08-1.56$ & 94 & $1.90-13.94$ & 52 & 1.36 & Yes \\
\hline 2005.47 .9 & 0.36 & 203 & 51 & $0.08-1.21$ & 105 & $2.93-16.77$ & 47 & 0.40 & Yes \\
\hline 2005.48 .7 & 0.83 & 202 & 36 & $0.07-1.43$ & 119 & $1.99-8.82$ & 47 & 7.61 & No \\
\hline All & & 795 & 194 & & 411 & & 190 & 0.96 & Yes \\
\hline
\end{tabular}

a $\chi^{2}$ values were calculated to test conformity to the model of a single locus with two co dominant alleles. The $\chi^{2}$ threshold for acceptance at $P=0.05$ is 5.99

The total above ground dry weights of the cannabinoid-free and the high content segregants were assessed as an indication of vigour. Per $F_{2}$ progeny, per segregant group the weights showed a Gaussian distribution. In three progenies the cannabinoid-free individuals on average had a ca. $10 \%$ higher dry weight than the high content individuals. In the 2005.48.7 progeny however, the average weight of the high content group exceeded that of the cannabinoid-free group by about $10 \%$.

Cannabinoid-free plants obtained in the course of the backcrossing program had increasingly more branching, a stronger fragrance and higher trichome density than the original USO-31 plants. In segregating progenies the different chemotypes were microscopically compared. Figure 3 shows images of different chemotypes in the 2005.45.13 $\mathrm{F}_{2}$. Bracteoles of cannabinoid-free plants all carried small, grey, dull trichomes of various shapes (Fig. 3a). Some were headless; some were pinhead and shrivelled, either flat, convex or concave. The high content CBD- and/or THC- predominant individuals all had big, round clear heads that sparkled under the lamp (Fig. 3c). The low content plants were almost indistinguishable from the cannabinoid-free plants except that their bracteoles showed an occasional small but bright trichome head (Fig. 3b). The high content CBG predominant plants from the 2005.45.13 $\mathrm{F}_{2}$ had big, round, opaque white heads (Fig. 3d), clearly distinct from the transparent ones occurring on the THC predominant segregants of the same progeny. The low content CBG predominant 2005.45.13 plants did not show opaque white trichome heads and were indistinguishable from the low content THC predominant plants, neither were white trichome heads observed in any of the cannabinoid-free plants of this progeny.

The cannabinoid-free homologues that were selected from $\mathrm{BC}_{2}$ generations, had a good semblance and fragrance of M3 and M16 but, unlike these 'originals', their mature inflorescences did not feel sticky.

Chemical comparison of cannabinoid-free and high content bulks

Yields and compositions of steam-distilled essential oils from bulked cannabinoid-free and bulked high content segregants of four $\mathrm{F}_{2}$ progenies are presented in Table 6. In three, the cannabinoid-free bulks contained less essential oil than the high content ones. In 2005.45.13, however, the cannabinoid-free bulk was slightly richer. No qualitative differences in the essential oil composition were found, only minor quantitative ones, which generally did not show a systematic pattern. The only consistent quantitative difference was found in caryophyllene oxide. In all four progenies it reached a higher proportion in the cannabinoid-free bulks than in the high content bulks. Table 7 presents the comparison of the different segregant bulks from 2003.8.21 and 2003.17.19 for a variety of compound classes. In general the differences between the entourages of the cannabinoid-free and the high content bulks were only quantitative. Limonene was an exception in that it was not detected in the cannabinoid-free bulks, whereas a minor presence was found in both of the high content bulks. However, the essential oil data in Table 6 does 

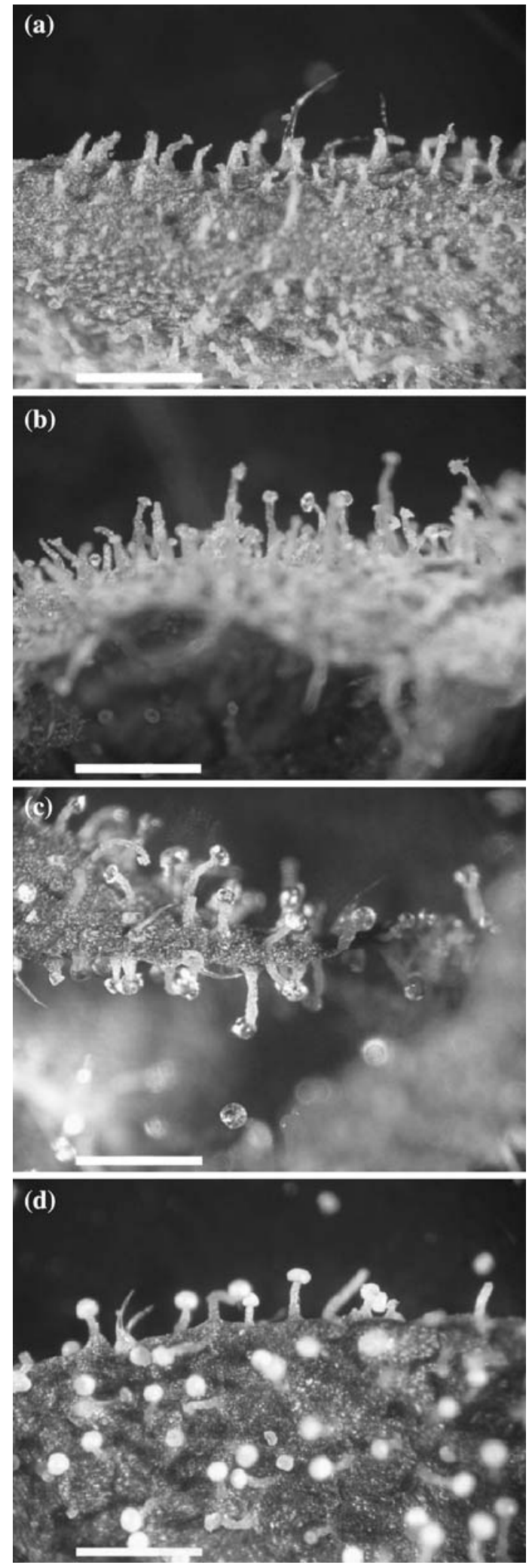

4Fig. 3 Microscopic images of the bracteole surfaces of different chemotype segregants of the 2005.45.13 $\mathrm{F}_{2}$. The bar in each photograph represents $500 \mu \mathrm{m}$. a Cannabinoidfree; b low content and THC predominant; $\mathbf{c}$ high content and THC predominant; d high content and CBG predominant (Photos by courtesy of T.J. Wilkinson)

not confirm this finding for the other $\mathrm{F}_{2} \mathrm{~s}$. Likewise, Table 7 does not show the difference in caryophyllene oxide as it appears in Table 6. Both progenies in Table 7 had consistently higher levels of four different triglycerides in the cannabinoid-free bulks than the high content bulks. Of the entourage compounds listed in the Tables 6 and 7, the occurrence of none appears to be critically associated with the presence or absence of cannabinoids.

\section{Discussion}

Genetic mechanism

The breeding experiments have demonstrated that a cross between a cannabinoid-free plant and a high cannabinoid content plant yields an $F_{1}$ with low cannabinoid content. Inbred, these $F_{1} s$ produce $F_{2} S$ that segregate into the discrete chemotypes, 'cannabinoid-free', 'low content' and 'high content' in a 1:2:1 monogenic ratio. This tripartite segregation can also be presented in binary form, with the chemotypes 'cannabinoids absent' and 'cannabinoids present' appearing in a 1:3 ratio. Inbred offspring from cannabinoid-free plants invariably remained cannabinoid-free. These results can be explained by postulating a single allelic locus with a common functional allele that allows cannabinoid synthesis and a rare null- or knockout allele that obstructs it. The finding that ca. $25 \%$ of the $\mathrm{F}_{2}$ plants was cannabinoid-free implies that the null allele is recessive and the functional dominant. However, the fact that, of the group with cannabinoids present, $2 / 3$ of the plants had contents that were much lower than the parental mean, indicates that in heterozygotes, the null allele strongly suppresses the expression of the functional one. At least one of the two USO-31 source plants with only a trace of cannabinoids must have represented the genotype null/functional. The pooled inbred offspring from these plants, which were used to pollinate M35 and 
Table 6 Yield and composition of steam-distilled essential oil from bulked cannabinoid-free (Zero) and bulked high content segregants of four $\mathrm{F}_{2}$ progenies. Oil yield is expressed as v/w ( $\mathrm{ml}$ per $100 \mathrm{~g}$ of dry Botanical Raw Material, a mixture of stem leaves, floral bracts and bracteoles). Terpene amounts are presented as peak area \% relative to the total peak area (set at $100 \%$ ), tr. indicates that a constituent is detectable but under the quantification threshold. The terpenes were analysed by GC-FID-MS

\begin{tabular}{|c|c|c|c|c|c|c|c|c|}
\hline \multirow{2}{*}{$\begin{array}{l}\mathrm{F}_{2} \text { progenies } \\
\text { Segregant bulks }\end{array}$} & \multicolumn{2}{|c|}{2005.45 .13} & \multicolumn{2}{|c|}{2005.46 .27} & \multicolumn{2}{|c|}{2005.47 .9} & \multicolumn{2}{|c|}{2005.48 .7} \\
\hline & Zero & High & Zero & High & Zero & High & Zero & High \\
\hline Oil yield & 0.65 & 0.57 & 0.67 & 0.87 & 0.28 & 0.87 & 0.41 & 0.63 \\
\hline \multicolumn{9}{|l|}{ Monoterpenes } \\
\hline Alpha-pinene & 16.64 & 11.83 & 28.53 & 26.80 & 10.27 & 2.86 & 33.52 & 22.53 \\
\hline Beta-pinene & 7.65 & 6.58 & 12.60 & 9.37 & 5.57 & 2.22 & 15.51 & 8.98 \\
\hline Myrcene & 51.10 & 42.11 & 34.16 & 42.86 & 19.84 & 41.45 & 24.82 & 36.47 \\
\hline Limonene & 4.76 & 4.53 & 6.41 & 7.41 & 7.27 & 5.54 & 5.17 & 4.58 \\
\hline Beta-ocimene & & & & & tr. & 9.58 & tr. & 8.60 \\
\hline Linalool & 1.62 & 2.78 & & & 10.48 & 2.95 & 2.91 & tr. \\
\hline Cis-verbenol & & & & & & & 1.73 & tr. \\
\hline Trans-verbenol & & & & & 3.31 & 0.00 & 2.61 & 0.00 \\
\hline \multicolumn{9}{|l|}{ Sesquiterpenes } \\
\hline Beta-caryophyllene & 3.90 & 12.25 & 7.28 & 8.35 & 7.97 & 15.93 & 4.73 & 9.84 \\
\hline Trans-alpha-bergamotene & 3.86 & 3.71 & 1.71 & tr. & & & & \\
\hline (z)-Beta-farnesene & 4.83 & 6.05 & 2.78 & 1.95 & tr. & 3.48 & tr. & 1.86 \\
\hline Alpha-caryophyllene & 3.04 & 6.83 & 3.27 & 3.26 & 7.88 & 7.68 & 2.12 & 3.69 \\
\hline (e)-Beta-farnesene & $\operatorname{tr}$. & 1.69 & & & & & & \\
\hline Gamma-gurjunene & & & & & $\operatorname{tr}$. & 1.78 & & \\
\hline Delta-guaiene & & & & & 3.64 & 4.67 & 1.67 & 3.44 \\
\hline Nerolidol & $\operatorname{tr}$. & 1.65 & & & & & & \\
\hline Unknown & & & & & tr. & 1.86 & & \\
\hline Caryophyllene oxide & 2.62 & $\operatorname{tr}$. & 3.25 & tr. & 13.43 & tr. & 5.19 & tr. \\
\hline Humulene epoxide II & & & & & 6.06 & tr. & & \\
\hline Alpha-bisabolol & & & & & 4.27 & tr. & & \\
\hline
\end{tabular}

M84, must have comprised the genotypes null/null, null/functional and functional/functional in unknown frequency. Fertilisation of M35 and M84 with null pollen would have resulted in the null/functional low content hybrids, which were actually found as a minority in the 2003.8 and $2003.17 \mathrm{~F}_{1}$ progenies, beside a majority of high content plants resulting from fertilisation by functional pollen.

In a null/null genotype not even CBG and/or CBGV are detectable, so the null allele must operate upstream of the previously postulated locus $B$ that controls the conversions of $\mathrm{CBG}(\mathrm{V})$ into $\mathrm{THC}(\mathrm{V})$ and CBD $(V)$ de Meijer et al. (2003) and the accumulation of CBG(V) (de Meijer and Hammond 2005) as well as the fixed locus $C$ that controls the conversion of CBG(V) into CBC(V) (de Meijer et al. 2009). The various dihybrid segregation ratios presented here indicate that the allelic locus regulating cannabinoid absence and presence segregates independently from locus $B$.

de Meijer et al. 2003 speculate that the postulated locus $A$, which governs the pathways towards either $\operatorname{CBG}\left(A_{\text {pe }}\right)$ or $\operatorname{CBGV}\left(A_{\mathrm{pr}}\right)$, has a null allele responsible for blocking cannabinoid synthesis. The current results conflict with this theory. The USO-31 source plants which contained cannabinoids, had chemotypes composed solely of pentyl cannabinoids. This state, according to the theory, would make their locus $A$ genotype $A_{\mathrm{pe}} / A_{\mathrm{pe}}$ or $A_{\mathrm{pe}} / A_{0}$. Had the absence of cannabinoids in certain USO-31 plants been due to a null allele in the homozygous state at locus $A$, the genotype of these plants would have been $A_{0} / A_{0}$. 
Table 7 The composition of bulked cannabinoid-free (Zero) and bulked high content segregants of two $\mathrm{F}_{2}$ progenies. Cannabinoids, carotenoids, chlorophylls and triglycerides were analysed by HPLC-UV, other compounds by GC-FID-MS

\begin{tabular}{|c|c|c|c|c|}
\hline \multirow{2}{*}{$\begin{array}{l}\mathrm{F}_{2} \text { progenies } \\
\text { Segregant bulks }\end{array}$} & \multicolumn{2}{|l|}{2003.8 .21} & \multicolumn{2}{|l|}{2003.17 .19} \\
\hline & Zero & High & Zero & High \\
\hline \multicolumn{5}{|l|}{ Cannabinoids $^{\mathrm{c}}$} \\
\hline CBDV & - & 0.06 & - & - \\
\hline THCV & - & - & - & 0.09 \\
\hline CBGV & - & - & - & 0.01 \\
\hline CBD & - & 0.48 & - & - \\
\hline $\mathrm{CBC}$ & - & 0.05 & - & 0.03 \\
\hline CBGM & - & 0.01 & - & - \\
\hline THC & - & 0.02 & - & 0.32 \\
\hline CBG & - & 0.21 & - & 0.06 \\
\hline $\mathrm{CBN}$ & - & - & - & 0.01 \\
\hline \multicolumn{5}{|l|}{ Triterpenes ${ }^{\mathrm{b}}$} \\
\hline Squalene & $4.1 \times 10^{7}$ & $7.9 \times 10^{7}$ & $2.1 \times 10^{7}$ & $1.9 \times 10^{7}$ \\
\hline Unidentified hydrocarbon & $5.2 \times 10^{8}$ & $5.4 \times 10^{8}$ & $1.1 \times 10^{8}$ & $1.6 \times 10^{8}$ \\
\hline Unidentified alcohol 1 & $3.8 \times 10^{8}$ & $5.1 \times 10^{8}$ & $1.1 \times 10^{8}$ & $3.3 \times 10^{8}$ \\
\hline Unidentified alcohol 2 & $1.3 \times 10^{8}$ & $1.3 \times 10^{8}$ & $5.5 \times 10^{7}$ & $1.4 \times 10^{8}$ \\
\hline \multicolumn{5}{|l|}{ Diterpenes ${ }^{\mathrm{c}}$} \\
\hline Phytol & 0.0587 & 0.0591 & 0.0511 & 0.0487 \\
\hline \multicolumn{5}{|l|}{ Sesquiterpenes ${ }^{\mathrm{c}}$} \\
\hline Beta-caryophyllene & 0.0043 & 0.0105 & 0.0022 & 0.0102 \\
\hline Alpha-caryophyllene & 0.0022 & 0.0037 & 0.0027 & 0.0035 \\
\hline Caryophyllene oxide & 0.0049 & 0.0041 & 0.0020 & 0.0041 \\
\hline Nerolidol & 0.0030 & 0.0024 & 0.0043 & 0.0027 \\
\hline \multicolumn{5}{|l|}{ Monoterpenes $^{\mathrm{c}}$} \\
\hline Alpha-pinene & 0.0010 & 0.0015 & 0.0015 & 0.0085 \\
\hline Myrcene & 0.0017 & 0.0057 & 0.0024 & 0.0180 \\
\hline Limonene & - & 0.0011 & - & 0.0015 \\
\hline Linalool & 0.0030 & 0.0053 & 0.0035 & 0.0053 \\
\hline \multicolumn{5}{|l|}{ Long-chain alkanes $^{\mathrm{b}}$} \\
\hline Nonacosane & $1.1 \times 10^{9}$ & $9.5 \times 10^{8}$ & $2.0 \times 10^{8}$ & $4.7 \times 10^{8}$ \\
\hline Heptacosane & $1.5 \times 10^{8}$ & $1.8 \times 10^{8}$ & $5.5 \times 10^{7}$ & $4.7 \times 10^{7}$ \\
\hline Pentacosane & $2.5 \times 10^{7}$ & $2.0 \times 10^{7}$ & $1.3 \times 10^{7}$ & $7.4 \times 10^{6}$ \\
\hline Hentriacontane & $2.7 \times 10^{8}$ & $1.6 \times 10^{8}$ & $4.2 \times 10^{7}$ & $7.3 \times 10^{7}$ \\
\hline \multicolumn{5}{|l|}{ Sterols ${ }^{\mathrm{b}}$} \\
\hline Sitosterol & $2.3 \times 10^{8}$ & $1.5 \times 10^{8}$ & $7.6 \times 10^{7}$ & $2.9 \times 10^{8}$ \\
\hline Campesterol & $6.6 \times 10^{7}$ & $4.0 \times 10^{7}$ & $1.3 \times 10^{7}$ & $5.9 \times 10^{7}$ \\
\hline Stigmasterol & $5.1 \times 10^{7}$ & $3.3 \times 10^{7}$ & $8.1 \times 10^{6}$ & $4.6 \times 10^{7}$ \\
\hline \multicolumn{5}{|l|}{ Fatty acids ${ }^{\mathrm{a}}$} \\
\hline Palmitic acid & $\checkmark$ & $\checkmark$ & $\checkmark$ & $\checkmark$ \\
\hline Linoleic acid & $\checkmark$ & $\checkmark$ & $\checkmark$ & $\checkmark$ \\
\hline Oleic acid & $\checkmark$ & $\checkmark$ & $\checkmark$ & $\checkmark$ \\
\hline Stearic acid & $\checkmark$ & $\checkmark$ & $\checkmark$ & $\checkmark$ \\
\hline Linolenic acid & $\checkmark$ & $\checkmark$ & $\checkmark$ & $\checkmark$ \\
\hline
\end{tabular}


Table 7 continued

\begin{tabular}{|c|c|c|c|c|}
\hline \multirow{2}{*}{$\begin{array}{l}\mathrm{F}_{2} \text { progenies } \\
\text { Segregant bulks }\end{array}$} & \multicolumn{2}{|l|}{2003.8 .21} & \multicolumn{2}{|l|}{2003.17 .19} \\
\hline & Zero & High & Zero & High \\
\hline \multicolumn{5}{|l|}{ Aldehydes ${ }^{\mathrm{b}}$} \\
\hline Octadecanal & $2.4 \times 10^{7}$ & $5.5 \times 10^{7}$ & $8.1 \times 10^{7}$ & $6.9 \times 10^{7}$ \\
\hline \multicolumn{5}{|l|}{ Vitamins ${ }^{\mathrm{b}}$} \\
\hline Vitamin E & $1.6 \times 10^{7}$ & $2.1 \times 10^{7}$ & $1.2 \times 10^{7}$ & $1.3 \times 10^{7}$ \\
\hline \multicolumn{5}{|l|}{ Carotenoids $^{\mathrm{a}}$} \\
\hline Beta-carotene & $v$ & $\checkmark$ & $\checkmark$ & $\checkmark$ \\
\hline \multicolumn{5}{|l|}{ Chlorophylls $^{\mathrm{a}}$} \\
\hline Chlorophyll a & $\checkmark$ & $\checkmark$ & $\checkmark$ & $\checkmark$ \\
\hline \multicolumn{5}{|l|}{ Triglycerides $^{\mathrm{d}}$} \\
\hline GGL & 49.13 & 22.67 & 39.07 & 32.81 \\
\hline GLL & 19.40 & 7.00 & 9.71 & 7.03 \\
\hline OLLn & 39.37 & 22.87 & 48.23 & 39.36 \\
\hline OLL & 20.14 & 6.21 & 15.53 & 10.80 \\
\hline
\end{tabular}

${ }^{a}$ Compounds scored as present $(\boldsymbol{})$

b Quantities expressed as GC-MS peak areas

c Quantities expressed as \% w/w contents

d Quantities expressed as HPLC-UV peak areas

When a pool of inbred offspring from low content USO-31 plants $\left(A_{\mathrm{pe}} / A_{0}\right)$ was used to pollinate the THCV predominant M35 $\left(A_{\mathrm{pr}} / A_{\mathrm{pr}}\right)$, it should then have resulted in an $A_{\mathrm{pr}} / A_{0}$ genotype for those of the $2003.17 \mathrm{~F}_{1}$ hybrids with a distinctively low cannabinoid content. When the low content $F_{1}$ individual 2003.17.19 was inbred, several purely pentyl cannabinoid chemotypes $\left(A_{\mathrm{pe}} / A_{\mathrm{pe}}\right)$ occurred in the 2003.17.19 $\mathrm{F}_{2}$, refuting the possibility that cannabinoid absence in USO-31 is attributable to a factor that is allelic to $A_{\text {pe }}$ and $A_{\text {pr. }}$ Furthermore, in the 2005.47.9 and 2005.48.7 $\mathrm{F}_{2} \mathrm{~S}$, there were similar $\mathrm{P}_{\mathrm{C} 3}$ distributions in the low- and the high cannabinoid content segregant groups. This indicates that the factor that regulates cannabinoid presence/absence inherits independently from the factor that controls the proportions of alkyl homologues.

We propose to situate the allele causing cannabinoid absence at a postulated locus ' $O$ '. Locus $O$ has the null allele $o$, which obstructs the cannabinoid synthesis in homozygous genotypes (o/o) and the functional allele $O$ that fully allows cannabinoid synthesis in homozygous $O / O$ plants. If a binary chemotype concept is used, only allowing for the conditions of 'cannabinoid presence' and 'cannabinoid absence', the functional allele dominates the null allele. This would concur with Mandolino's (2004) interpretation of the paper by Sytnik and Stelmah (1999). However, all the $F_{1}$ plants resulting from contrasting crosses and about $50 \%$ of the plants in segregating $\mathrm{F}_{2} \mathrm{~s}$, had a cannabinoid content that was much closer to the zero value of the cannabinoid-free parent than to that of the high content parent. With a chemotype definition based on total cannabinoid content, one would consider the null allele as being incompletely dominant over the functional one.

It has been previously stated that the total cannabinoid content is a polygenic character, heavily affected by the environment and showing a Gaussian distribution within progenies (de Meijer et al. 2003). This fully applies for progenies solely consisting of the common $\mathrm{O} / \mathrm{O}$ plants. However, our model should include the distinction that, in o/o genotypes, the normal polygenic character of total cannabinoid content is overruled by the monogenic mechanism that dictates a discrete state of cannabinoid absence. In $O / o$ genotypes this monogenic mechanism has a decisive, strongly suppressant effect on the degree of cannabinoid accumulation and leads to a discrete low content chemotype. Even so, within an $\mathrm{O} / o$ low content segregant group, the polygenic nature of total 
cannabinoid content is noticeable through its Gaussian distribution pattern.

A new variant of the $\mathrm{CBG}$ accumulating factor

The high content-CBG predominant segregants of the 2005.45.13 $\mathrm{F}_{2}$ showed an unusually high purity of $\mathrm{CBG}$ in the total cannabinoid fraction. Irrespective of the alkyl side chain, the $\mathrm{CBG}(\mathrm{V})$ proportion was $99.75 \%$ and the only detectable minor cannabinoid was CBD $(0.25 \%)$. The genetic mechanism of CBG predominance has been previously explored (de Meijer and Hammond 2005), using an Italian source population for the $B_{0}$ allele. The CBG accumulating factor from the Ukrainian USO-31 source behaves similarly. It is allelic to $B_{\mathrm{D}}$ and $B_{\mathrm{T}}$ and shows monogenic segregation; it can be readily introduced into high content plants and it has a residual, albeit extremely limited, CBD synthase activity. The $B_{0}$ allele derived from the Italian source had a much higher residual CBD synthase activity which, in homozygotes, led to maximum CBG proportions of ca. 86-88\% and a complementary fraction of CBD. We can safely speculate that the CBG accumulating factor from USO-31 differs from the Italian one. Its residual CBD synthase activity suggests that this allele is also a mutation from $B_{\mathrm{D}}$ and hence is a member of a series of alleles encoding CBD synthase isoforms with differential catalytic abilities. The opaque white trichome heads of the high contentCBG predominant 2005.45.13 plants are probably due to the ample presence of solid CBG in the secretory cavities. Although not reported by de Meijer and Hammond (2005), the CBG predominant plants derived from the Italian breeding source also carry opaque trichome heads. In the low cannabinoid content segregant group of the 2005.45.13 progeny, $25 \%$ of the individuals were CBG predominant but these had grey, dull trichomes like their THC predominant sister plants. This is probably because trichomes contain sufficient solvent to dissolve small amounts of CBG. Apparently, in their pursuit of creating a THC-free fibre cultivar, the breeders of USO-31 employed two different genetic factors. In our terminology these are: allele $o$ at locus $O$ that categorically obstructs cannabinoid synthesis, and an allele $B_{0}$ at locus $B$ that obstructs the further conversion of $\mathrm{CBG}(\mathrm{V})$. The statement by Gorshkova et al. (1988) that plants carrying trichomes with white heads contain no cannabinoids, appears to be a misinterpretation, maybe because either their methods or definitions did not recognise $\mathrm{CBG}$ as a cannabinoid.

Morphological and biochemical effects

of the cannabinoid knockout factor

Cannabinoid-free segregants resulting from backcrosses with high content drug clones had stalked glandular trichomes in normal densities, but the trichome heads were dull and much smaller than those of their high cannabinoid content sister plants. Nevertheless, the trichomes of cannabinoid-free segregants appear to be functional metabolic organs. Chemical comparison of contrasting segregant bulks did not reveal big differences in the content and composition of volatile terpenes, the production of which requires functional trichomes. The absence of cannabinoids is probably the cause of the small trichome heads, rather than being a result of them. The bracts and bracteoles of low content plants were microscopically almost indistinguishable from the cannabinoid-free plants except that they showed an occasional small but bright trichome head. In these plants the small amount of cannabinoids appears to be concentrated in just a few inflated trichomes and not evenly distributed throughout. Cannabinoids are synthesised in the trichome secretory cavities (Sirikantaramas et al. 2005) and translocation from there is unlikely. This implies that in $O / o$ plants, the ability to synthesise cannabinoids is confined to a small minority of the trichomes. The abundant presence of apparently functional trichomes on our cannabinoid-free plants obtained through (back)crossing with high content materials, rules out the idea that the absence of cannabinoids is due to (1) a disrupted morphogenesis of the glandular trichomes. Hence it appears that the cannabinoid knockout factor is not derived from the gland-free plants reported by Gorshkova et al. (1988). It is more likely that the absence of cannabinoids is attributable to the blockage of one or more biochemical pathways that are crucial for the formation of precursors upstream of CBG. As the chemical entourage of cannabinoid-free plants is intact, the obstacle is probably not in (2) the DOX pathway towards IPP. According to Fellermeier et al. (2001) the IPP incorporated into cannabinoids via GPP is derived from the DOX pathway in the plastids. Monoterpenes, diterpenes (phytol) and 
Locus $C$

Fixed

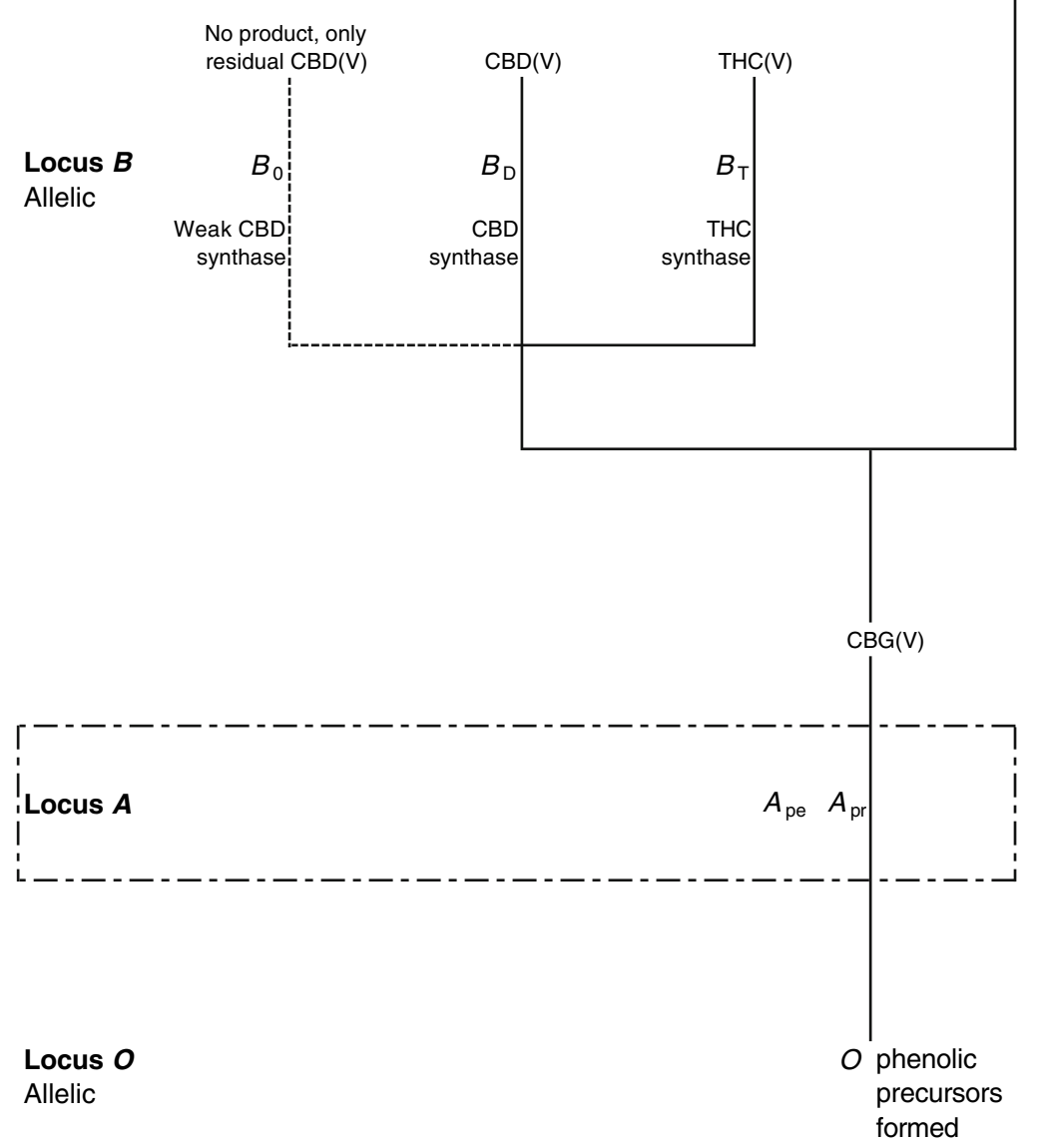

No cannabinoid synthesis

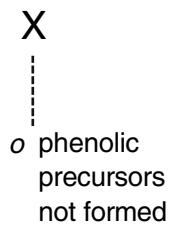

Fig. 4 Updated model for the regulation of the cannabinoid biogenesis. The allelic locus $O$ regulates the discrete states of cannabinoid presence and absence. The functional allele ' $O$ ' allows normal cannabinoid synthesis in $O / O$ homozygotes, the null allele ' $o$ ' blocks cannabinoid synthesis in $o / o$ homozygotes and strongly suppresses it in $O / o$ heterozygotes. Allele $o$ probably blocks the polyketide pathway towards the cannabinoid phenolic precursors. Locus $O$ inherits independently from

carotenoids are also uniquely synthesised in the plastids (Samuelsson 1999) and so one could conclude that the IPP incorporated in these compounds, as with cannabinoids, is derived from the DOX the chemotype loci that determine cannabinoid composition. The current and previously described experiments do not cover the hypothetical locus $A$ that governs the alkyl chain length of cannabinoids and remains to be investigated. The conversions and accumulation of $\mathrm{CBG}(\mathrm{V})$ are regulated by the loci $B$ and $C$ (de Meijer et al. 2003, 2009; de Meijer and Hammond 2005)

pathway. Therefore, if the absence of cannabinoids were due to a blockage of the DOX pathway that hampered the synthesis of the GPP, there should also be a negative effect on the synthesis of monoterpenes, 
diterpenes and carotenoids, which is demonstrably not true. Sesquiterpenes, sterols and triterpenes are uniquely synthesised in the cytoplasm, presumably from MVA derived IPP (Samuelsson 1999) and do not share a fundamental pathway with the terpenoid moiety of cannabinoids. Consequently, the absence of cannabinoids due to a metabolic obstacle should not suppress their presence. Another option (3), is that the knockout allele encodes a defective form of the enzyme GOT (Fellermeier and Zenk 1998) which catalyses the condensation of resorcinolic acids (OA and DA) with GPP into CBG(V). However, with such a mechanism one would expect an accumulation of $\mathrm{OA}$ and/or DA in the cannabinoid-free segregants. Our GC method for cannabinoid analysis detects the decarboxylated forms of both acids but they were not observed in any of the cannabinoid-free chromatograms. The most plausible hypothesis for the absence of cannabinoids therefore appears to be (4), a blockage in the polyketide pathway towards the phenolic moieties OA and DA. Whatever the mechanism of the cannabinoid knockout factor is, one would expect that a functional system would dominate a non-functional one, and so it remains obscure as to why the heterozygous genotypes $(\mathrm{O} / \mathrm{o})$ have such heavily suppressed cannabinoid synthesis.

The essential oil comparison and the chromatographic fingerprinting of contrasting segregant bulks demonstrated that, except for the cannabinoids, all the compound classes monitored were present in both segregant groups. The levels of the compounds did vary between the contrasting segregant groups but not usually systematically. The quantitative differences between contrasting bulks could be attributable to the fact that, in cannabinoid-free plants, the trichome heads, as the metabolic centres for a range of endproducts, are not inflated with cannabinoids. This may change the physical environment in which the reactions occur so as to quantitatively affect the synthesis of entourage compounds. Large amounts of unincorporated basic cannabinoid precursors may also affect the equilibriums of other biosynthetic reactions.

It was noticed that although the cannabinoid-free homologues closely resemble the two production clones, their mature inflorescences do not feel sticky. The resinous stickiness that is typical of the floral leaf surface of common Cannabis plants is apparently caused by the mixture of cannabinoids and terpenes. If cannabinoids are missing, the plants have a dry surface.
Ecological and evolutionary implications

In heterozygous genotypes $(\mathrm{O} / \mathrm{o})$, the knockout allele strongly suppresses the cannabinoid synthesis, so it would be very conspicuous were it to be introduced into normally high content drug type populations. Over time, due to long distance wind pollination, such introgressions are likely, so it is remarkable that there are, apart from a few papers on fibre hemp, no references to the knockout factor. One could speculate as to whether this mutation is natural yet extremely rare, or recently man-made. Various theories, all relating to the defence against biotic and abiotic stress (Pate 1998), attribute ecological benefits to the presence of cannabinoids which would explain the rarity of the knockout allele. Recently, Morimoto et al. (2007) reported on the ability of cannabinoids to induce necrotic cell death in the Cannabis leaf cells. They suggested that these compounds play a role in the plant's defence system and in the process of leaf senescence. Appendino et al. (2008) reported potent antibacterial effects for the major cannabinoids. In our glasshouse experiments, the absence of cannabinoids did not obviously weaken the plants nor affect the self-fertility in inbreeding cycles. In three out of four segregating progenies, the cannabinoid-free individuals actually produced, on average, more biomass than the high cannabinoid content individuals.

\section{Practical applications}

Apart from its utilisation in fibre hemp breeding, the knockout allele may also be of use in the development of Cannabis based pharmaceuticals. Cannabinoid-free clones with a non-cannabinoid entourage closely resembling that of pharmaceutical clones would provide suitable placebo material for clinical trials. They would also allow experiments focusing on cannabinoid-entourage interactions. To this purpose, we have developed a range of cannabinoid-free clones with mutually contrasting monoterpene compositions, the data of which are not presented here.

\section{Updated genetic model}

We have extended the genetic model for the regulation of Cannabis chemotype by introducing a locus $O$, with a dominant functional allele ' $O$ ' that allows 
normal cannabinoid synthesis in $\mathrm{O} / \mathrm{O}$ homozygotes, and a recessive null allele ' $O$ ' that blocks the cannabinoid synthesis in $o / o$ homozygotes and strongly suppresses it in $O / O$ heterozygotes. In the sequence of biosynthetic events from precursors to cannabinoid end products, locus $O$ undoubtedly operates upstream of $\mathrm{CBG}(\mathrm{V})$. The most plausible explanation appears that $o$ blocks the polyketide pathway towards olivetolic- and divarinic acid. Locus $O$ is independent from the previously presented loci $B$ and $C$ and from a genetic factor that governs the alkyl chain length of cannabinoids. In order to complete the inheritance model for the currently known cannabinoid chemotypes (Fig. 4), the genetic control of the cannabinoid alkyl chain length remains to be investigated.

Acknowledgments We thank Mirta Micheler, James Amos and Andrew Bracking for the chemical comparison of segregant bulks.

\section{References}

Anonymous (1996) Nouvelles variétés de lins et chanvre. Semences et Progres 96:110-111

Appendino G, Gibbons S, Giana A, Pagani A, Grassi G, Stavri M, Smith E, Rahman MM (2008) Antibacterial cannabinoids from Cannabis sativa: a structure-activity study. J Nat Prod 71:1427-1430. doi:10.1021/np8002673

de Meijer EPM, Hammond KM (2005) The inheritance of chemical phenotype in Cannabis sativa L. (II): cannabigerol predominant plants. Euphytica 145:189-198. doi: 10.1007/s10681-005-1164-8

de Meijer EPM, Bagatta M, Carboni A, Crucitti P, Moliterni VMC, Ranalli P, Mandolino G (2003) The inheritance of chemical phenotype in Cannabis sativa L. Genetics 163:335-346

de Meijer EPM, Hammond KM, Micheler M (2009) The inheritance of chemical phenotype in Cannabis sativa L. (III): variation in cannabichromene proportion. Euphytica 165:293-311. doi:10.1007/s10681-008-9787-1

Fellermeier M, Zenk MH (1998) Prenylation of olivetolate by a hemp transferase yields cannabigerolic acid, the precursor of tetrahydrocannabinol. FEBS Lett 427:283-285. doi: 10.1016/S0014-5793(98)00450-5

Fellermeier M, Eisenreich W, Bacher A, Zenk MH (2001) Biosynthesis of cannabinoids, incorporation experiments with ${ }^{13} \mathrm{C}$-labeled glucoses. Eur J Biochem 268:15961604. doi:10.1046/j.1432-1327.2001.02030.x

Gorshkova LM, Senchenko GI, Virovets VG (1988) Method of evaluating hemp plants for content of cannabinoid compounds [Russian]. Referativnyi Zhurnal 12.65.322

Hillig KW (2002) Letter to the editor. JIH 7:5-6

Mandolino G (2004) Again on the nature of inheritance of chemotype. JIH 9:5-7
Morimoto S, Komatsu K, Taura F, Shoyama Y (1997) Enzymological evidence for cannabichromenic acid biosynthesis. J Nat Prod 60:854-857. doi:10.1021/np970210y

Morimoto S, Komatsu K, Taura F, Shoyama Y (1998) Purification and characterization of cannabichromenic acid synthase from Cannabis sativa. Phytochemistry 49:15251529. doi:10.1016/S0031-9422(98)00278-7

Morimoto S, Tanaka Y, Sasaki K, Tanaka H, Fukamizu T, Shoyama Y, Shoyama Y, Taura F (2007) Identification and characterization of cannabinoids that induce cell death through mitochondrial permeability transistion in Cannabis leaf cells. J Biol Chem 282:20739-20751. doi: 10.1074/jbc.M700133200

Pacifico D, Miselli F, Micheler M, Carboni A, Ranalli P, Mandolino G (2006) Genetics and marker-assisted selection of the chemotype in Cannabis sativa L. Mol Breed 17:257-268. doi:10.1007/s11032-005-5681-x

Pate DW (1998) The phytochemistry of Cannabis: its ecological and evolutionary implications. In: Ranalli P (ed) Advances in hemp research. The Haworth Press, New York, pp 21-42

Raharjo TJ, Chang WT, Verberne MC, Peltenburg-Looman AMG, Linthorst HJM, Verpoorte R (2004a) Cloning and over-expression of a cDNA encoding a polyketide synthase from Cannabis sativa. Plant Physiol Biochem 42:291-297. doi:10.1016/j.plaphy.2004.02.011

Raharjo TJ, Chang WT, Choi YH, Peltenburg-Looman AMG, Verpoorte R (2004b) Olivetol as a product of a polyketide synthase in Cannabis sativa L. Plant Sci 166:381-385. doi:10.1016/j.plantsci.2003.09.027

Samuelsson G (1999) Drugs of natural origin, 4th edn. Swedisch Pharmaceutical Press, Stockholm, p 551

Shoyama Y, Hirano H, Nishioka I (1984) Biosynthesis of propyl cannabinoid acid and its biosynthetic relationship with pentyl and methyl cannabinoid acids. Phytochemistry 23:1909-1912. doi:10.1016/S0031-9422(00)84939-0

Sirikantaramas S, Taura F, Tanaka Y, Ishikawa Y, Morimoto S, Shoyama Y (2005) Tetrahydrocannabinolic acid synthase, the enzyme controlling marijuana psychoactivity, is secreted into the storage cavity of the glandular trichomes. Plant Cell Physiol 46:1578-1582. doi:10.1093/ $\mathrm{pcp} / \mathrm{pci} 166$

Sytnik VP, Stelmah AF (1999) The character of inheritance of differences in cannabinoid content in hemp (Cannabis sativa L). J Int Hemp Association 6:8-9

Taura F, Morimoto S, Shoyama Y, Mechoulam R (1995) First direct evidence for the mechanism of delta-1-tetrahydrocannabinolic acid biosynthesis. J Am Chem Soc 38:97669767. doi:10.1021/ja00143a024

Taura F, Morimoto S, Shoyama Y (1996) Purification and characterization of cannabidiolic-acid synthase from Cannabis sativa L. J Biol Chem 271:17411-17416. doi: 10.1074/jbc.271.29.17411

Virovets VG (1996) Selection for non-psychoactive hemp varieties (Cannabis sativa L.) in the CIS (former USSR). J Int Hemp Assoc 3:13-15

Virovets VG (1998) Interview. J Int Hemp Assoc 5:32-34

Virovets VG, Senchenko GI, Gorshkova LM, Sashko MM (1991) Narcotic activity of Cannabis sativa L and prospects of its selection for decreased content of cannabinoids. Agric Biol 1:35-49 Russian 
Virovets VG, Scherban I, Orlov N (1997) Selektion auf niedrige Gehalt der Cannabinoid und hohe Produktivität im Schaffungsprogramm von Hanfsorten (Cannabis sativa
L.), die keine narkotische Ativität besitzen. Proceedings of the symposium Bioresource Hemp 97, Frankfurt am Main, pp135-153 